\title{
Effects of Alcoholic Extract of Myrtus communis L. on the Hypothalamic- Pituitary-Thyroid Axis in Rats
}

\author{
Saeed Changizi-Ashtiyani, ${ }^{1}$ Mehrdad Shariati, ${ }^{2}$ Mokhtar Mokhtari, ${ }^{2}$ Davoud Moghadamnia, ${ }^{3}$ \\ and Moslem Fereidooni,"
}

${ }^{1}$ Department of Physiology, Arak University of Medical Sciences, Arak, IR Iran

${ }^{2}$ Department of Biology, Kazeroon Branch, Islamic Azad University, Kazeroon, IR Iran

${ }^{3}$ Department of Physiology, Fars Sciences and Researches Branch, Islamic Azad University, Shiraz, IR Iran

*Corresponding author: Moslem Fereidooni, Department of Biology, Kazeroon Branch, Islamic Azad University, Kazeroon, IR Iran. E-mail: farydoni1360@gmail.com

Received: October 8, 2014; Accepted: November 11, 2014

\begin{abstract}
Background: Myrtus communis leaves have the potential to affect thyroid hormone functions.
Objectives: In this study, the effects of hydroalcoholic extract of M. communis on the hypothalamus-pituitary-thyroid axis and histological changes were studied.

Materials and Methods: In this experimental study, 40 male rats were divided in 5 groups $(n=8)$ : control, sham, and three experimental groups which received the extract of $M$. communis leaves in a minimal ( $0.75 \mathrm{mg} / \mathrm{kg})$, Medium $(1.5 \mathrm{mg} / \mathrm{kg}$ ) and maximal amounts ( $3 \mathrm{mg} /$ $\mathrm{kg}$ ), respectively. At the end of the 15th day blood samples were collected to measure triiodothyronine $\left(\mathrm{T}_{3}\right)$, thyroxine $\left(\mathrm{T}_{4}\right)$ and thyroidstimulating hormone (TSH) and to study thyroid gland tissue

Results: Serum levels of $\mathrm{T}_{4}$ and TSH in groups receiving maximum dose of the extract showed a significant decrease compared to sham group $(\mathrm{P}<0.05)$.

Conclusions: It is probable that some compounds in the alcoholic extract of M. communis leaves may be cause changes in serum TSH concentration and thyroid hormones.
\end{abstract}

Keywords: Thyroid; Pituitary; Triiodothyronine; Thyroxine; Thyroid-stimulating hormone; Rat; Myrtus communis leaf

\section{Background}

Thyroid hormones are known as catabolic hormones involved in regulating a wide range of metabolic processes. Naturally, numerous food and environmental factors can also be involved in the biosynthesis and metabolism of thyroid hormones [1]. Myrtus communis L. commonly named as myrtle is a wild evergreen plant, found mainly in the central and southern parts of Iran. M. communis L. is from Myrtaceae family, species of Myritiflora and a Rosidae subclass. M. communis leaves contain various chemical compounds such as tannins, flavonoids, saponins and unsaturated fatty acids. The percentages of chemical compounds in M. communis are as follows: 1, 8-cineol (18.2\%), linalool acetate (16.3\%), myrtenyl acetate (14.5\%), linalyl acetate (6.7\%), alpha-terpineol (6.5\%), alpha-pinene (6.4\%), geranyl acetate $(5.5 \%)$, limonene (3.4\%), geraniol, neryl acetate and methyl eugenol (between 1 and $2 \%$ ) and also a little amount of vitamin C [2]. This plant has been used as medicine, food, and spice since long ago. In traditional medicine its fruit has been used to treat infectious diseases and the leaves have been prescribed as a wound antiseptic, antiinflammatory, cathartic, hypoglycemic, mouthwash, and a treatment for urinary tract diseases [3].

\section{Objectives}

Regarding the unique properties of the thyroid gland in the production and secretion of thyroid hormones and the mechanisms that control it and also the diversity of the ingredients found in this plant, we decided to examine the possible effects of alcoholic extract of M. communis leaves on the hypothalamic-pituitary-thyroid axis (HPT axis) and body weight in laboratory animals during the study period.

\section{Materials and Methods}

\subsection{Animal Experiments}

In this experimental study, used 40 adult male Wistar rats weighing approximately $200 \pm 20$ g. All the study procedures on animals were conducted in compliance with ethical codes. To get the animals adapted to the testing environment.

Extraction method: First in spring M. communis leaves were collected from Zarjan district of Fasa, Iran. After the genus and family were confirmed by a botanist, the leaves were washed and dried in shade (Figure 1). Considering the values of $\mathrm{LD}_{50}$ (lethal dose, $50 \%$ ) and the fact

Copyright (C) 2015, Zahedan University of Medical Sciences. This is an open-access article distributed under the terms of the Creative Commons Attribution-NonCommercial 4.0 International License (http://creativecommons.org/licenses/by-nc/4.0/) which permits copy and redistribute the material just in noncommercial usages, provided the original work is properly cited. 


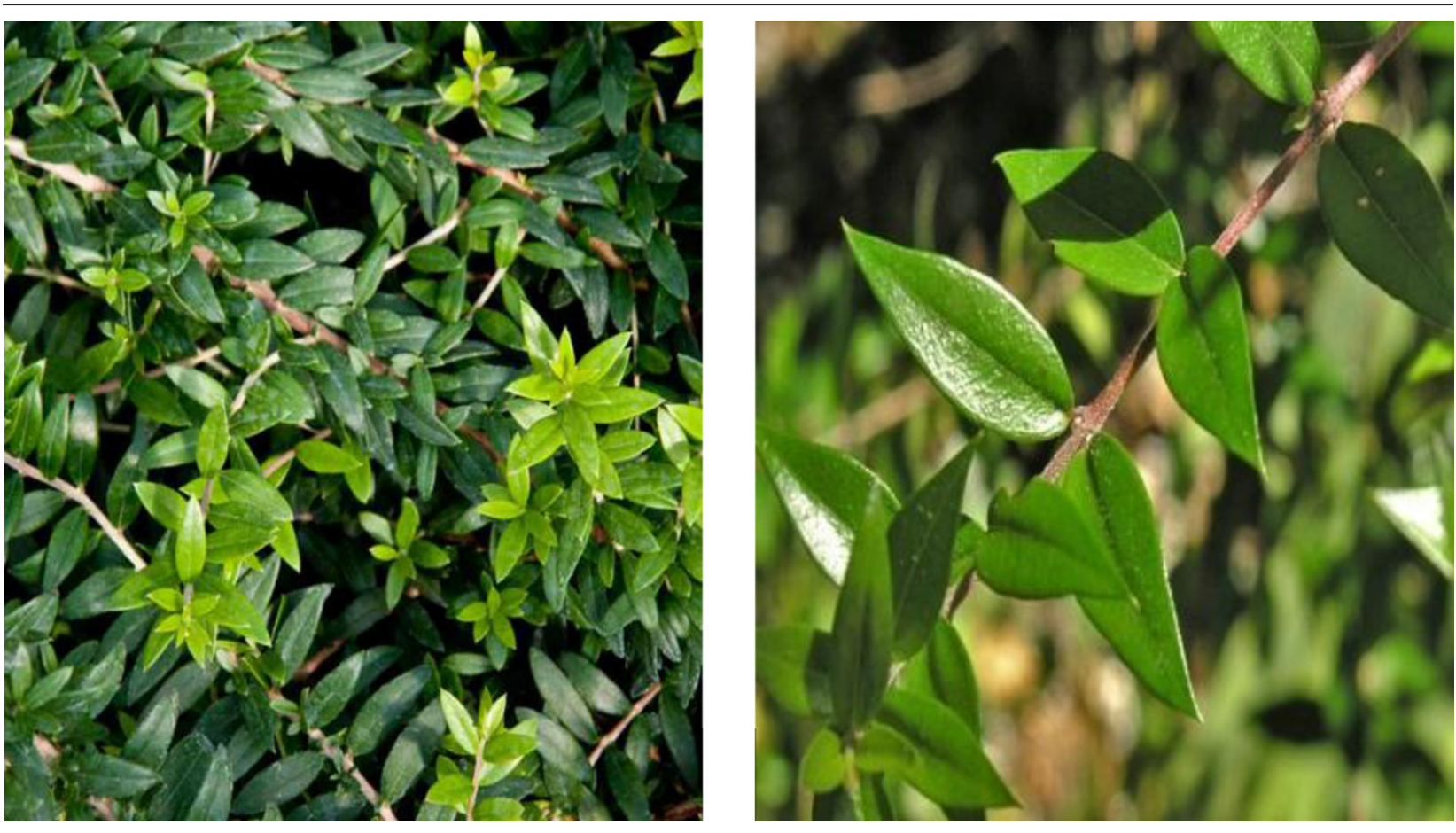

Figure 1. Aerial Parts of Myrtus communis L

that the aqueous extract is more toxic than the hydroalcoholic one, the latter was used in this study [4]. Six hundred grams of the leaf powder were mixed with $500 \mathrm{~mL}$ of distilled water and ethyl alcohol $96 \%$ in the ratio of 1:1. Then the mixture was stirred in a shaker for 48 hours in the dark. After that the contents of the flask were passed through filter papers and then were poured into a vacuum rotating vaporizer machine at $50^{\circ} \mathrm{C}$. The concentrated extract was then poured into sterile Petri dishes and was oven dried at $40^{\circ} \mathrm{C}$. The dried powder was then collected and mixed with distilled water at concentrations of $0.75,1.5$ and $3 \mathrm{mg} / \mathrm{mL}$ [5].

\subsection{Experimental Design}

The rats were divided into five groups as follows $(n=8)$ : Group I: The control group (rats of the group underwent no stress such as injection, oral gavage and etc).

Group II: The sham rats in this group were daily given $0.2 \mathrm{~mL}$ of distilled water by gavage.

Group III: The experimental group consisted of three subgroups which were given different amounts of alcoholic extract of M. communis leaves with $0.75 \mathrm{mg} / \mathrm{kg} /$ day.

Group IV: 1.5 mg/kg/day and Group V: 3 mg/kg/day for 15 days by gavage.

At the end of 15th day, the weight of the rats was measured and then the rats were anesthetized by ether and blood sampling from the heart was done. Blood samples obtained from each rat was centrifuged at 4,000 rpm for 15 minute to separate the serum from the clot. Then, samples were kept at the temperature of $-20^{\circ} \mathrm{C}$ until hormone measurement.

\subsection{Histological Studies}

Using surgical scissors, the skin under the jaw was cut out and the thyroid gland was removed from the surrounding tissues. After washing with saline, the thyroid glands were transferred to coded containers with $10 \%$ buffered formalin. After 24 hours, this formalin was replaced with $10 \%$ buffered formalin and was stored in a refrigerator until histology operation. After routine histological operations, cross section and staining were done with hematoxylin and eosin; finally, the samples were evaluated by light microscope with a magnification of 100x $[4,5]$. To measure the level of thyroid hormones by radioimmunoassay and RIA device (10227 Prague10 Czech, ImmunoTech) and a radioimmunoassay kit (Pars Azmoon) were used. Dlaplus LOT: MC1A5 was used to evaluate the intra and inter-test variation coefficient of triiodothyronine $\left(\mathrm{T}_{3}\right)$ and thyroxine $\left(\mathrm{T}_{4}\right)$ levels.

The mean values (mean $\pm \mathrm{SD}$ ) of measured thyroid hormones concentrations in different groups were statistically analyzed by one way ANOVAs and Tukey test. Statistical analysis was performed by using SPSS-11.5 $(\mathrm{P}<0.05)$.

\section{Results}

The effect of alcoholic extract of M. communis leaves on body weight in rats treated with the extract shows; there is not a statistically significant difference between sham and 
Changizi-Ashtiyani S et al.

Table 1. The Comparison Between Effect of Different Doses of Myrtus communis on Weights and Parameters of Thyroid Function

\begin{tabular}{|c|c|c|c|c|c|}
\hline & Control & Sham & $0.75 \mathrm{mg} / \mathrm{kg}$ & $1.5 \mathrm{mg} / \mathrm{kg}$ & $3 \mathrm{mg} / \mathrm{kg}$ \\
\hline Weight, g & $217.62 \pm 5.9$ & $215.9 \pm 5.65$ & $206.25 \pm 7.3$ & $204.75 \pm 7.4$ & $203.37 \pm 8.34$ \\
\hline $\mathrm{T}_{3}, \mathrm{ng} / \mathrm{dL}$ & $58 \pm 1.62$ & $56.5 \pm 2.33$ & $53 \pm 1.75$ & $50 \pm 4.92$ & $48 \pm 2$ \\
\hline$T_{4}, \mu g / d L$ & $2.29 \pm 0.3$ & $2.08 \pm 0.4$ & $2.07 \pm 0.3$ & $2 \pm 0.4$ & $1.4 \pm 0.3^{\mathrm{a}}$ \\
\hline TSH, ng/mL & $0.14 \pm 0.06$ & $0.14 \pm 0.04$ & $0.13 \pm 0.06$ & $0.12 \pm 0.04$ & $0.09 \pm 0.02^{a}$ \\
\hline
\end{tabular}

${ }^{\mathrm{a}}$ Indicates a significant difference $(\mathrm{P}<0.05)$ between the experimental groups and control and sham group.

control and others groups (Table 1 ). Regarding the effect of different doses of alcoholic extract of $M$. communis leaves on thyroid-stimulating hormone (TSH), a significant reduction was seen in the group receiving $3 \mathrm{mg} / \mathrm{kg} /$ day of the extract compared to the control and sham groups; however, this reduction was not significant in groups receiving $1.5 \mathrm{mg} / \mathrm{kg} /$ day and $0.75 \mathrm{mg} / \mathrm{kg} /$ day (Table 1). When examining the effect of different doses of alcoholic extract of $M$. communis leaves on $\mathrm{T}_{4}$. It was found that only the group receiving $3 \mathrm{mg} / \mathrm{kg} /$ day of the extract showed a significant reduction in this hormone in comparison to the control and sham groups $(\mathrm{P}=0.01)$ (Table 1$)$.

No significant differences were noticed in $\mathrm{T}_{3}$ concentration in rats treated with ethanol extract of the leaves of M. communis compared to control and sham groups (Table 1).

\subsection{The Impact of M. communis Leaf Extract on Thy- roid Tissue Changes}

Statistical results from this study indicate that thyroid histomorphology including changes in thickness of hyaline membrane vessel wall, did not show any necrotic follicles, signs of inflammatory response or necrotic cells in the follicles. Also regarding the studies on thyroid tissues no differences were observed in different groups and doses.

\section{Discussion}

According to the results of this study, different values of M. communis leaf extracts had no effect on body weight. The values of the TSH and $\mathrm{T}_{4}$ hormones in the experimental groups receiving $3 \mathrm{mg} / \mathrm{kg} /$ day of the $M$. communis leaf extract showed a significant decrease compared to the control and sham groups. But the value of $\mathrm{T}_{3}$ did not show any significant change. $M$. communis leaf extract contains various phenolic compounds and also vitamin $\mathrm{C}$ that have anti-obesity properties and are irritants to dopamine in the nervous system and thereby they reduce the appetite and prevent weight gain [6]. Since carvacrol is one of the main constituents of M. communis, it increases the activity the pentose phosphate pathway which in turn, provides the energy needed for lipogenesis [2]. Therefore, it was reasonable for us to expect an increase in body weight during the experiment. However this did not happen which might be due to the short duration of the study. As M. communis leaf extract is rich in polyphenolic compounds such as tannins, it is able to inhibit mono amino oxidase enzyme (MAO) and in this way it can interfere in the action of neurotransmitters in the brain. The use of MAO inhibitors in rats can change TSH release patterns, resulting in decreased transport of iodine [6, 7]. Thyroid MAO enzyme is involved in the biosynthesis of thyroid hormones due to its ability to produce hydrogen peroxide [8].

When MAO is inhibited, the concentration of potent neurotransmitters such as dopamine increases which exert their inhibitory effects on the release of TSH stimulation via thyrotropin-releasing hormone (TRH) [9].

Dopamine neurotransmitter suppresses intracellular $\mathrm{Ca}^{2+}$ concentration. $\mathrm{Ca}^{2+}$ ion is essential in the metabolism of iodine in the thyroid gland and is also involved in the oxidation of $\mathrm{I}_{2}$. Studies have shown that TSH needed sufficient amount of I- to inhibit the hydrolysis of thyroglobulin (to produce $\mathrm{T}_{4}$ and $\mathrm{T}_{3}$ ). Apparently, by the suppression and removal of $\mathrm{Ca}^{2+}$ ions, dopamine reduces the concentration of these ions in thyrotrophic cells and thus decreases TSH synthesis [10]. By binding to $\mathrm{D}_{2}$ receptors, dopamine inhibits adenylate cyclase which leads to the prevention of cAMP and the reduction of TSH gene transcription and the inhibition of its secretion. As a result, TSH cannot act on its target cells; thereby a reduction in $\mathrm{T}_{4}$ secretion occurs [11]. Other compounds such as cineol present in M. communis leaf extract can inhibit the enzyme acetylcholinesterase and thereby can increase the level of acetylcholine and by inhibiting the indirect effect of GABA on TSH secretion, can prevent the secretion of this hormone from the hypothalamus and subsequently can decrease TSH and $\mathrm{T}_{4}[12]$.

M. communis leaves contain various chemical compounds such as tannins, flavonoids, saponins and unsaturated fatty acids. In vitro, flavonoids are able to increase iodide uptake and expression of sodium iodide symporter (NIS). Flavonoids are phenolic polyhydroxy compounds which are not only able to modulate NIS and thyroperoxidase as a key enzyme in the biosynthesis of thyroid hormones but also have anti-proliferative properties. Goncalves et al. [13] showed that the consumption of flavonoid rutin led to a decrease in serum $\mathrm{T}_{3}$ and $\mathrm{T}_{4}$, without changes in TSH and could significantly increase hypothalamic, pituitary and brown adipose tissue type 2 deiodinase. This could also end in a decrease in the activities of liver type 1 deiodinase. Rutin treatment also significantly increases thyroid iodide uptake possibly by increasing NIS expression, which may 
be secondary to increased TSH response and may be due to increased expression of TSH receptors. Therefore, flavonoids are able to increase thyroid iodide uptake with no specific changes on thyroid functions. In a study, De Souza Dos Santos et al. [14] showed that flavonoids can reduce thyroperoxidase activity and thus increase TSH, leading to goiter that it is more common in children. Flavonoids can facilitate the tissues access to thyroid hormones either by inhibiting the activity of deiodinase or by removing $\mathrm{T}_{4}$ from transthyretin. Catalases and flavonoids in the leaves of $M$. communis have antioxidant properties. Thyroid hormones increase metabolic activities and subsequently increase oxygen consumption which will therefore result in oxidative stress, noradrenaline oxidation; reactive oxygen species (ROS) and hydrogen peroxide are produced during normal metabolism. The results of the study supported the idea that flavonoids and catalases present in M. communis leaves were effective in protecting against oxidative stress resulted from the action of thyroid hormones because of their antioxidant properties [15]. As the plant contains a high diversity and variety of ingredients each of which can be responsible for its physiological and pharmacological effects, it is not possible to express the mechanisms of these effects with ultimate certainty.

\section{Acknowledgements}

This paper is taken from the results of the MA thesis No. 15230519871019 that has been carried out with the assistance of the research deputy of Kazeron Islamic Azad University whose kind help we wish to appreciate

\section{Authors' Contributions}

Mehrdad Shariati and Mokhtar Mokhtari have been involved in study design and experimental investigation. Davoud Moghadamnia and Moslem Fereidooni contributed in sample collection and were responsible for functional tests. Saeed Changizi-Ashtiyani was in writing the draft, charge for data analysis and editing the draft.

\section{Funding/Support}

Kazeroon University of Medical Sciences.

\section{References}

1. Shekar-Forosh S, Ashtiyani SC, Akbar-Pour B. The effect of Physalis alkekengi alcoholic extract on concentrations thyroid hormones in rats. Zahedan J Res Med Sci. 2012;13(9):1-7.

2. Malekpour A, Dehghani S, Zahedi S, Eskandari F. Effects of the hydro-ethanol extract of Myrtus communis L. on blood glucose level and histopathological changes in alloxan-induced diabetic rats. Middle-East J Sci Res. 2012;12(4):517-22.

3. Johari H, Nozari M, Moghtari M, Zamani Z, Yazdani M. The effect of myrtus communis extract on liver enzymes and blood biochemical factors in diabetic adult male rats. Zahedan J Res Med Sci. 2014;16(10):12-7.

4. Hosseinzadeh H, Khoshdel M, Ghorbani M. Antinociceptive, anti-inflammatory effects and acute toxicity of aqueous and ethanolic extracts of Myrtus communis L. Aerial parts in mice. Acupunct Meridian Stud. 2011;4(4):242-7.

5. Zaidi TM, Khan AA, Hasan BM, Faruqi AN. Carbimazole induced thyroid histopathy in albino rats during development. J Anat Soc India. 2004;53(2):14-7.

6. Serra PA, Migheli R, Rocchitta G, Taras MG, Mura MP, Delogu MR, et al. Role of the nitric oxide/cyclic GMP pathway and ascorbic acid in 3-morpholinosydnonimine (SIN-1)-induced increases in dopamine secretion from PC12 cells. A microdialysis in vitro study. Neurosci Lett. 2003;353(1):5-8.

7. Rajeswari A, Sabesan M. Inhibition of monoamine oxidase-B by the polyphenolic compound, curcumin and its metabolite tetrahydrocurcumin, in a model of Parkinson's disease induced by MPTP neurodegeneration in mice. Inflammopharmacology. 2008;16(2):96-9.

8. Stipcevic T, Kusacic-Kuna S, Dezeljin M, Dodig D, Korsic M, Pivac N et al. Platelet serotonin concentration and monoamine oxidase activity in hypothyroid patients. Horm Res. 2009;71(4):207-12.

9. Masini-Repiso AM, Cabanillas AM, Andrada MC, Coleoni AH Monoamine oxidase A mediates iodotyrosine formation in duced by monoamines in bovine thyroid particulate fraction. Horm Metab Res. 1990;22(2):80-4.

10. Topliss D. Alterations in the Thyroid Axis in Critical Illness: A Brief Review. Int JEndocrinol Metab. 2009;7(4):248-54.

11. Barrett KE, Barman SM, Boitano S, Brooks H. Ganong's Review of Medical Physiology, 24th Edition. 24 ed. New York: McGraw Hill Professional; 2012. p. 768.

12. Kapaki E, Paraskevas GP, Mantzou E, Papapostolou A, Alevizaki M, Vassilopoulos D. Thyroid function in patients with Alzheimer disease: implications on response to anticholinesterase treatment. Alzheimer Dis Assoc Disord. 2006;20(4):242-7.

13. Goncalves CF, Santos MC, Ginabreda MG, Fortunato RS, Carvalho DP, Freitas Ferreira AC. Flavonoid rutin increases thyroid iodide uptake in rats. PLoS One. 2013;8(9):e73908.

14. De Souza Dos Santos MC, Goncalves CF, Vaisman M, Ferreira AC de Carvalho DP. Impact of flavonoids on thyroid function. Food Chem Toxicol. 2011;49(10):2495-502.

15. Sumbul S, Ahmad MA, Asif M, Akhtar M. Myrtus communis Linn A review. Indian J Nat Prod Resour. 2011;2(4):395-402. 